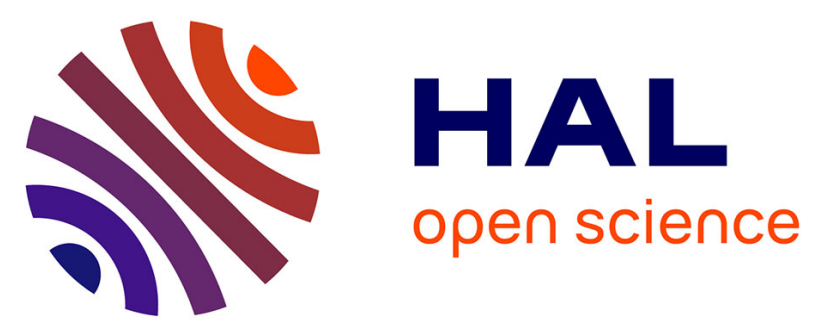

\title{
OPTICAL ABSORPTION SPECTRA OF LIQUID ALKALI HALIDES-F-CENTER GENERATION AT VERY HIGH TEMPERATURES
}

S. Hosokawa, S. Yamada, K. Tamura

\section{- To cite this version:}

S. Hosokawa, S. Yamada, K. Tamura. OPTICAL ABSORPTION SPECTRA OF LIQUID ALKALI HALIDES-F-CENTER GENERATION AT VERY HIGH TEMPERATURES. Journal de Physique IV Proceedings, 1991, 01 (C5), pp.C5-141-C5-146. 10.1051/jp4:1991517 . jpa-00250641

\section{HAL Id: jpa-00250641 https://hal.science/jpa-00250641}

Submitted on 1 Jan 1991

HAL is a multi-disciplinary open access archive for the deposit and dissemination of scientific research documents, whether they are published or not. The documents may come from teaching and research institutions in France or abroad, or from public or private research centers.
L'archive ouverte pluridisciplinaire HAL, est destinée au dépôt et à la diffusion de documents scientifiques de niveau recherche, publiés ou non, émanant des établissements d'enseignement et de recherche français ou étrangers, des laboratoires publics ou privés. 


\title{
OPTICAL ABSORPTION SPECTRA OF LIQUID ALKALI HALIDES-F-CENTER GENERATION AT VERY HIGH TEMPERATURES
}

\author{
S. HOSOKAWA, S. YAMADA and K. TAMURA \\ Faculty of Integrated Arts and Sciences, Hiroshima University, Hiroshima 730, Japan
}

\begin{abstract}
We have measured optical absorption coefficients of liquid alkali halides such as $\mathrm{NaCl}, \mathrm{KCl}$ and $\mathrm{CsCl}$ up to very high temperatures and found that there appears a new absorption band originated from F-center even in "pure" alkali halides by raising temperature, which is known to be generated usually by the addition of small amount of alkali metals to liquid alkali halides. The measurements have been performed using sapphire cell, the use of which is necessary to avoid a chemical reaction between the hot sample and the optical cell. The absorption band becomes large with increasing temperature and disappears again with decreasing temperature. The logarithmic plots of the area of the absorption bands versus reciprocal temperature for these liquids lie on the straight lines, which suggests that the F-center are generated by the thermal activation.
\end{abstract}

\section{Introduction}

A considerable attention has been paid on the electronic and structural properties of liquid alkali halides because these may exhibit a nonmetal-metal transition by the addition of alkali metal. In the limit of dilute metal concentration, several experimental $/ 1 /$ and theoretical $/ 2 /$ investigations, especially of the optical absorption spectrum, clearly indicate that the valence electrons of added alkali metal are localized into the potential well provided by the coordination shell of positive ions, which is the liquid-state analogue of the F-center of the solid state. Such an F-center model for electronic bound state in the dilute solution of alkali metal is fully consistent with the evidence on the pure liquid alkali halides obtained by neutron diffraction experiment $/ 3$ / and by computer simulation $/ 4 /$, which show a high degree of short-range order, that is, each halogen ion is surrounded by rather well-defined shell of alkali ions. This first neighbour shell can be expected to provide the attractive well binding the electron when it replaces a negative ions. Thus, the behavior of localized electrons in liquid alkali halides is considered to parallel what occurs of F-center in the solid state.

On the basis of this background, we have examined the possibility that F-center is thermally generated in the pure liquid alkali halides. It has long been recognized that pure solid alkali halides are transparent even at elevated temperature in spite that there may be a substantial concentration of lattice vacancies /5/ in thermal equilibrium. As is also well known, pure liquid alkali halides are transparent in the vinicity of the melting point. Therefore, it seems unlikely to con- 
sider that there exist observable F-centers in thermal equilibrium states of pure alkali halides. Indeed, F-centers generated in pure liquid alkali halides by a optical interband-excitation disappear in the short period $/ 6 /$. As far as we know, no attention has been paid to such a fundamental problem of whether there exist F-centers in pure liquid alkali halides in the thermal equilibrium or not, so far. In this paper we report the results of the optical absorption coefficient, $\alpha$, for pure liquid alkali halides such as $\mathrm{NaCl}, \mathrm{KCl}$ and $\mathrm{CsCl}$ in the wide temperature region up to their boiling points, about $1500^{\circ} \mathrm{C}$.

\section{Experimental}

For the measurements of $\alpha$ of liquid alkali halides at very high temperatures up to about $1500^{\circ} \mathrm{C}$, liquid sample must be contained by an optically transparent material having sufficiently high strength and resistance to the chemical corrosion by hot liquid alkali halides. We have developed an optical cell made of sapphire. The cell assembly is illustrated in figure 1. Two sapphire tubes with outer diameter of $6.5 \mathrm{~mm}$ and inner diameter of $4 \mathrm{~mm}$ were prepared. The length of the

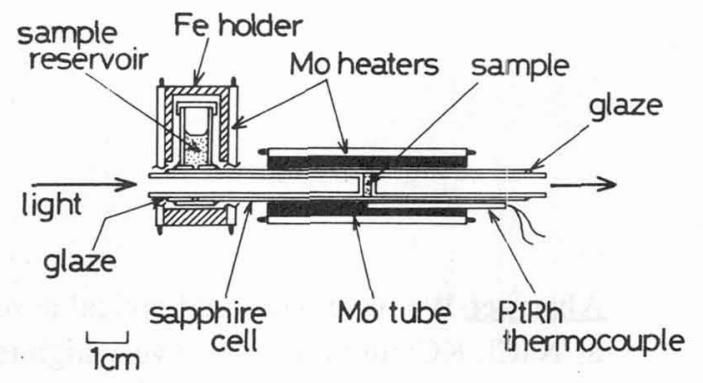

Figure 1.

The construction of the sapphire cell used for the optical absorption measurements. longer tube was $55 \mathrm{~mm}$ and the shorter one $45 \mathrm{~mm}$. Each of the tubes had one closed end, which was made by drilling a hole in a single crystal sapphire rod using diamond tools. Both of the outer and inner surfaces of the closed end were polished to be optically flat. The thickness of the closed-end wall was $1 \mathrm{~mm}$ or less. It should be noticed that this enabled us to measure $\alpha$ of liquid alkali halides in the photon-energy range up to about $6 \mathrm{eV}$ without being disturbed by the strong optical absorption of sapphire at the time when a long sapphire rod is used. These tubes were inserted into another open polycrystal-sapphire tube having inner diameter of $6.5 \mathrm{~mm}$, outer diameter of $8 \mathrm{~mm}$ and length of $90 \mathrm{~mm}$, in such a way that the closed-ends of the inner tubes faced each other with a uniform gap between them. As shown in the figure, the sapphire components were cemented together with high temperature glaze (Owen-Illinois Inc. Type 01328-C).

The cell was heated by a heating element of Mo wire. As seen in the figure the Mo heater was set around a Mo tube which kept the temperature of the sample space uniform. The temperature was measured by two $\mathrm{Pt}-30 \% \mathrm{Rh}: \mathrm{Pt}-6 \% \mathrm{Rh}$ thermocouples which were inserted into the holes drilled in the Mo tube, and were in close contact with the outer sapphire tube in the vinicity of the sample space. A sample reservoir was connected to the outside of the sapphire tube and encased with a Fe holder. The sample reservoir was maintained at a temperature about $50^{\circ} \mathrm{C}$ above the melting point of the sample during the measurements.

The optical cell was positioned in a cylindrical water-cooled chamber with optical windows of quartz. Figure 2 shows the side view of the chamber. As indicated in the figure, light beams passed through the quartz windows, the closed-ends of sapphire tubes and liquid sample. Hermetic seals were used for taking out the heater electrodes and thermocouples.

We used the commercial samples with the purity of $99.999 \%$. The sample space was filled with liquid sample in the following way. First, the chamber was evacuated and the sample space was heated to a temperature around $850^{\circ} \mathrm{C}$. Then, the solid sample loaded in the reservoir was 


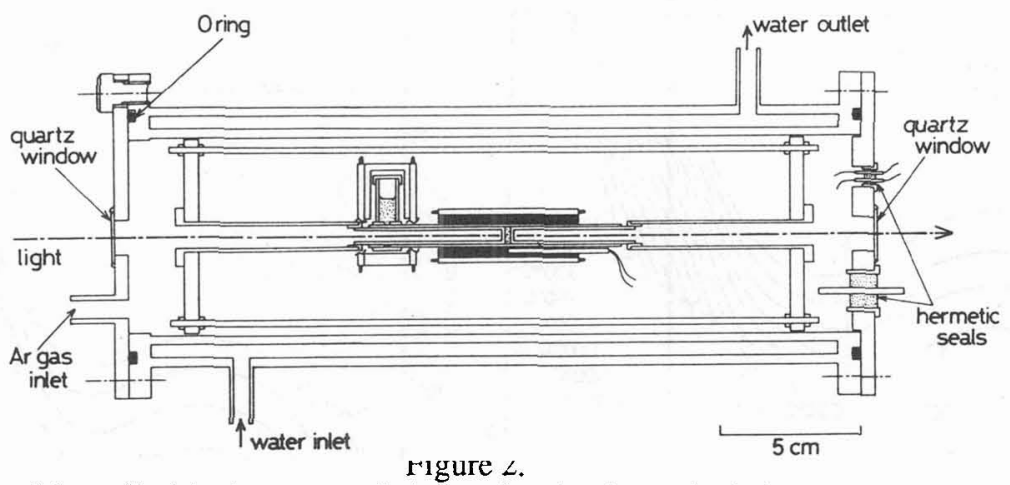

A side view of the cylindrical water-cooled chamber for the optical absorption measurements.

fused by heating it to a temperature $50^{\circ} \mathrm{C}$ above the melting point. Finally, He or Ar gas at atmospheric pressure was introduced into the chamber to force the fused sample to the sample space through a narrow channel between the outer and inner sapphire tubes. The open space in the chamber was filled with glass-wool to obtain good thermal insulation and to prevent convection of $\mathrm{He}$ or Ar gas.

We measured $\alpha$ using Jasco CT-25GD spectrometer in the wide photon wavelength range from 240 to $2500 \mathrm{~nm}$, which corresponds to the energy range from about 0.5 to $5.2 \mathrm{eV}$. In order to separate the transmitting lights through the sample and the strong radiations from the hot sample itself, we employed the method of lock-in detection. For the derivation of $\alpha$ from the mea-

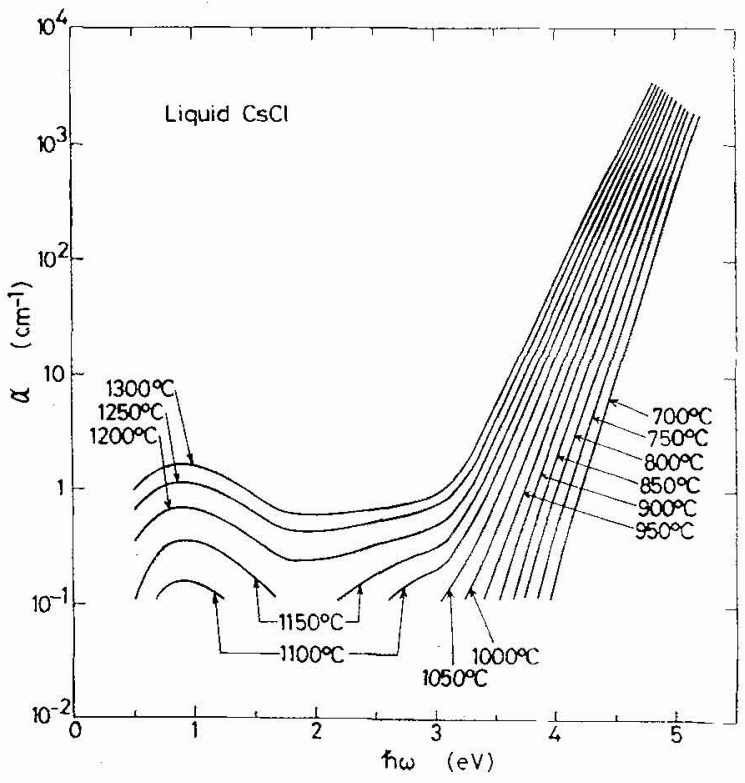

Figure 3.

The logarithmic plots of the optical absorption coefficient, $\alpha$, as a function of photon energy, $\hbar \omega$, for liquid $\mathrm{CsCl}$ at various temperatures. sured optical transmittance, we took account for various corrections, of which the following three were important; optical reflectance, temperature variations of the sample thickness and those of the optical absorption of the sapphire cell.

\section{Results and Discussion}

Figure 3 shows the logarithmic plots of $\alpha$ of liquid $\mathrm{CsCl}$ as a function of photon energy at various temperatures up to $1300^{\circ} \mathrm{C}$. The melting temperature, $T_{m}$, is $645^{\circ} \mathrm{C}$. The optical path lengths of the cells used for the measurements were $1 \mathrm{~cm}, 0.3$ $\mathrm{mm}$ and $30 \mu \mathrm{m}$, which enabled us to measure $\alpha$ in the absorption range from $10^{-1}$ to $3 \times 10^{3} \mathrm{~cm}^{-1}$. As clearly seen in the figure, the absorption curves can be decomposed into two parts: the high absorption region with exponential variation and distinct ab- 


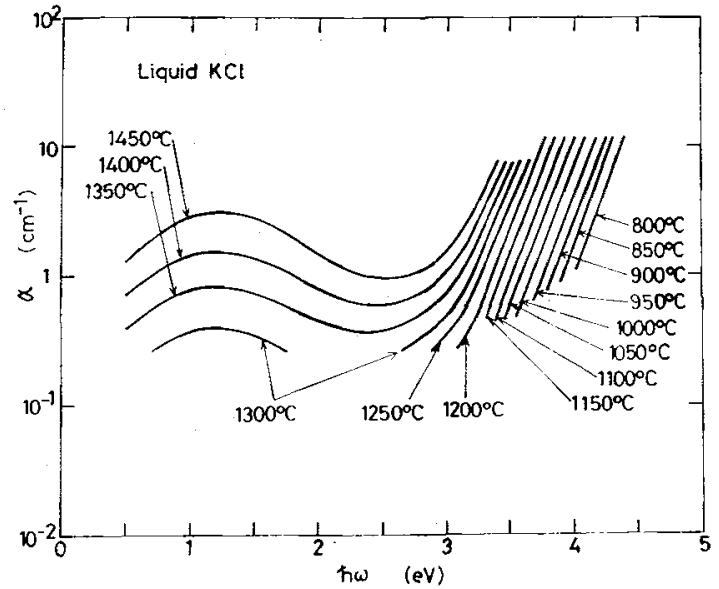

Figure 4

The logarithmic plots of $\alpha$ versus $\hbar \omega$ for liquid $\mathrm{KCl}$ at various temperatures.

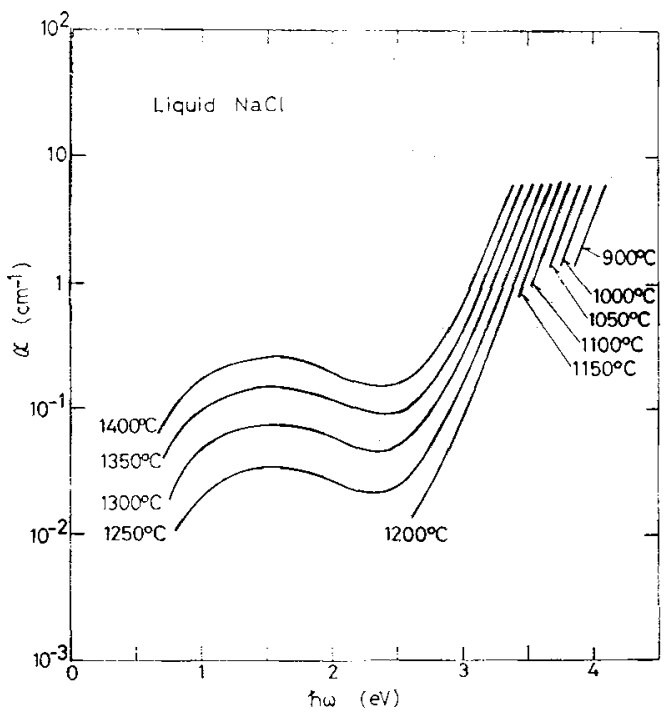

Figure 5

The logarithmic plots of $\alpha$ versus $\hbar \omega$ for liquid $\mathrm{NaCl}$ at various temperatures.

sorption bands in the low absorption region. The curves of $\alpha$ in the high absorption region shifts to low energy side with increasing temperature and the slope becomes small. Note that all curves extrapolated to the higher absorption region seem to be focused on a fixed point. The most interesting feature of the spectra is the appearance of new absorption bands in the low absorption region. Such a band was not observed near the melting point using the cell with the optical path length of $1 \mathrm{~cm}$. With increasing temperature, however, a new band appears and grows up as seen in the figure. It should be noticed that the band disappears again with decreasing temperature. The position of the band maximum is about $0.92 \mathrm{eV}$, which coincides to that for F-center in the $\mathrm{Cs}-\mathrm{CsCl}$ dilute solution $77,8 /$, and shifts slightly to the low energy side with increasing temperature.

Figure 4 shows the absorption spectra of liquid $\mathrm{KCl}\left(\mathrm{T}_{\mathrm{m}}=770^{\circ} \mathrm{C}\right)$ in the low absorption region. It is clear that a new absorption band appears at about $1.22 \mathrm{eV}$, which coincides that for Fcenter in $\mathrm{K}-\mathrm{KCl}$ dilute solution $77,8,9 /$, and becomes large with increasing temperature. With decreasing temperature it disappears again as that in liquid $\mathrm{CsCl}$. Figure 5 shows the absorption spectra for liquid $\mathrm{NaCl}\left(\mathrm{T}_{\mathrm{m}}=801^{\circ} \mathrm{C}\right)$ in the low absorption region. A new absorption band also appears at about $1.55 \mathrm{eV}$ which is the same energy for F-center in $\mathrm{Na}-\mathrm{NaCl}$ dilute solution /9,10/. Note that the absorption bands are not so dominant in liquid $\mathrm{NaCl}$ compared with those for liquid $\mathrm{KCl}$ and $\mathrm{CsCl}$.

Each curve of the absorption bands was found to be well described using one Gaussian. Figure 6 shows the logarithmic plots of the area of the absorption bands as a function of reciprocal temperature. It is clear that the plots lie on straight lines. From these findings together with the information on the maximum position of the absorption bands, we consider that the absorption bands are originated from the F-center thermally generated in the equilibrium state of pure liquid alkali halides. Activation energies estimated from the slopes are 2.7, 3.0 and $2.9 \mathrm{eV}$ 
for liquid $\mathrm{CsCl}, \mathrm{KCl}$ and $\mathrm{NaCl}$, respectively. We consider that these activation energies might be those for thermally creating F-centers together with the counterparts such as $\mathrm{Cl}_{2}{ }^{-}$defects which are the liquid-state analogues of $\mathrm{V}_{\mathrm{k}}$-centers in the solids and are necessary to conserve the charge neutrality. In the present experiments we have not observed any absorption bands due to such defects as $\mathrm{Cl}_{2}{ }^{-}$; the absorption bands may be located in the rather high energy region and merge into the exponential tail of the fundamental absorption edge at very high temperatures. It should be noticed that in our speculation F-centers are not generated through the process of the excitation of electrons beyond the band gap. We have no

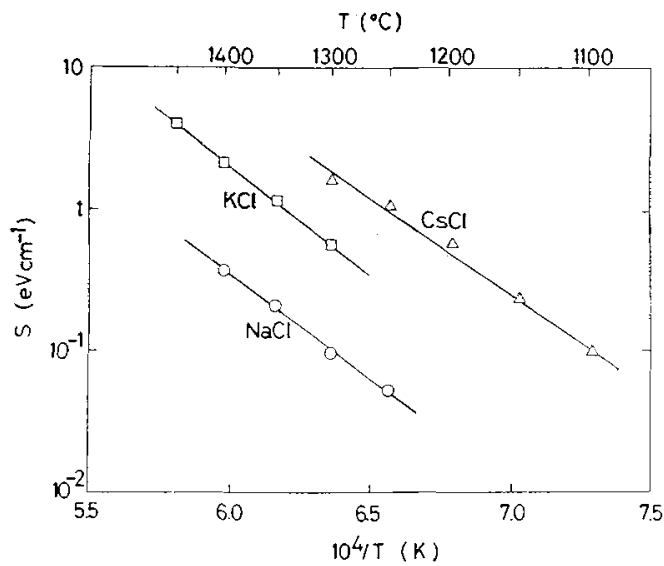

Figure 6.

The logarithmic plots of the area of the absorption band, $S$, as a function of reciprocal temperature, $1 / \mathrm{T}$, for liquid $\mathrm{CsCl}, \mathrm{KCl}$ and $\mathrm{NaCl}$. theoretical calculations of energies required to create a pair of $\mathrm{F}$-center and $\mathrm{Cl}_{2}{ }^{-}$defect in pure solid or liquid alkali halides. It is interesting, however, that the creation energies of Schottky type vacancies, that is, a pair of cation and anion vacancies in the solid alkali chlorides, are about 2.2 $\mathrm{eV} / 5 /$ which is slightly smaller than our activation energies.

The number density of F-centers generated in liquid $\mathrm{KCl}$ at $1450^{\circ} \mathrm{C}$ is estimated to be $5 \times 10^{16} \mathrm{~cm}^{-3}$ or less, which is obtained by comparing the value of $\alpha$ of $F$-center band in pure liquid $\mathrm{KCl}$ with those of $\mathrm{K}-\mathrm{KCl}$ dilute solution $/ 8 /$. As is easily estimated using the values of the activation energies and the number density of F-centers, it is evident that the observation of F-

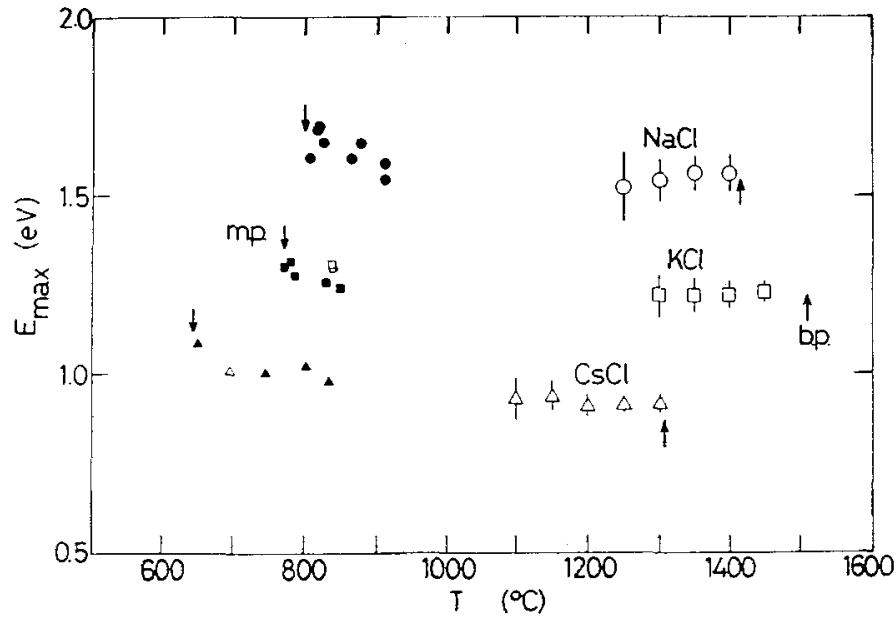

Figure 7.

Temperature variations of the energy of the F-center band maximum, Emax, of pure Iiquid $\mathrm{NaCl}(\mathrm{O}), \mathrm{KCl}(\square)$ and $\mathrm{CsCl}(\Delta)$ together with the data obtained for electron-injected liquid alkali halides $(\bullet, \bullet, \Delta:$ small $) / 11 /$ and those for alkali-alkali halide dilute solutions ( $\bullet, \Delta$ : small) 18\%. Downward arrows indicate the melting points and upward ones the boiling point. 
centers is difficult near the melting points in liquids as well as in hot solids.

Figure 7 shows the temperature variations of the energy at the maximum of the absorption band, $E_{\max }$, for pure liquid alkali halides together with the data obtained for electron-injected liquid alkali halides /11/ and those for alkali-alkali halide dilute solutions /8/: Open circles, squares and triangles show the data obtained by the present experiments, small-closed ones those for electron-injected liquid alkali halides and small-open ones those for alkali-alkali halide dilute solutions.It is clear that the consistencies between these data are quite good; especially, plots of the present data for liquid $\mathrm{CsCl}$ lie on the smooth curve extrapolated through data points indicated by small-closed and small-open triangles. The maximum energy of the F-center absorption band in liquid $\mathrm{CsCl}$ shifts to lower energy side with increasing temperature, but those for $\mathrm{KCl}$ and $\mathrm{NaCl}$ change little.

In summary, we have performed the measurements of $\alpha$ of pure liquid $\mathrm{NaCl}, \mathrm{KCl}$ and $\mathrm{CsCl}$ in the wide temperature range up to about $1500^{\circ} \mathrm{C}$ using the optical cells made of sapphire developed in our laboratory and found that F-centers can be generated by raising temperature even in pure liquid alkali halides. Further experiments are now in progress for other liquid alkali halides.

\section{Acknowledgements}

The authors are grateful to Professors M. Watabe and K. Hoshino for valuable discussions. This work is partly supported by the Grant-in-Aid for Scientific Research Fund from the Ministry of Education, Science and Culture of Japan.

\section{References}

/1/ see for example, WARREN W W Jr., in "Advances in Malten Salt Chemistry", Vol. 4, Mamantov G and Braunstein J, Ed., Plenum, New York, 1981

12/ SANATORE G, PARRINELLO M and TOSI M P, Philos. Mag. 41 (1980) 595

13/ MITCHELL E W J, PONCET P F J and STEWART R J, Philos. Mag. 34 (1976) 721, EDWARDS F G, ENDERBY J E, HOWE R A and PAGE D I, J. Phys. C 8 (1975) 3483, DERRIEN J Y and DUPUY J, J. Phys. Paris 36 (1975) 191

/4/ WOODCOCK L V and SINGER K, Trans. Faraday Soc. 67 (1971) 12, SANGSTER M J L and DIXON M, Adv. Phys. 25 (1976) 247

15/ see for example, MARCH N H and TOSI M P, "Coulomb Liquids", Academic Press, London, 1984, p.11-13

/6/ WARREN W W Jr., CAMPBELL B F and BRENNERT G F, Phys. Rev. Lett. 58 (1987) 941

7/ ROUNSA VILLE J F and LAGOWSKI J J, J. Phys. Chem. 72 (1968) 1111

18/ FREYLAND W, GARBADE K, HEYER H and PFEIFFER, J. Phys. Chem. 88 (1984) 3745

/9/ MOLLWO E, Nachr. Ges. Wiss. Göttingen. 1 (1935) 203

/10/ GRUEN D M, KRUMPELT M and JOHNSON I, in "Malten Salts: Characterization and Analysis", Mamantov G, Ed., Marcel Dekker, New York, 1969, p.169

/11/ SCHMITT W and SCHINDEWOLF U, Ber. Bunsenges. Phys. Chem. 81 (1977) 584 